\title{
Improving carotenoid extraction from tomato waste by pulsed electric fields
}

\section{Elisa Luengo, Ignacio Álvarez and Javier Raso*}

Tecnología de los Alimentos, Facultad de Veterinaria, Universidad de Zaragoza, Zaragoza, Spain

\section{Edited by:}

António Manuel Peres, Instituto

Politécnico de Bragança, Portugal

Reviewed by:

Olivia Rodrigues Pereira, Instituto Politécnico de Bragança, Portugal Luís Guimarães Dias, Instituto

Politécnico de Bragança, Portugal

*Correspondence:

Javier Raso, Tecnología de los Alimentos, Facultad de Veterinaria, Universidad de Zaragoza, c/Miguel Servet 177, Zaragoza 50013, Spain e-mail: jraso@unizar.es
In this investigation, the influence of the application of pulsed electric fields (PEFs) of different intensities $(3-7 \mathrm{kV} / \mathrm{cm}$ and $0-300 \mu \mathrm{s})$ on the carotenoid extraction from tomato peel and pulp in a mixture of hexane:acetone:ethanol was studied with the aim of increasing extraction yield or reducing the percentage of the less green solvents in the extraction medium. According to the cellular disintegration index, the optimum treatment time for the permeabilization of tomato peel and pulp at different electric field strengths was $90 \mu \mathrm{s}$. The PEF permeabilization of tomato pulp did not significantly increase the carotenoid extraction. However, a PEF treatment at $5 \mathrm{kV} / \mathrm{cm}$ improved the carotenoid extraction from tomato peel by $39 \%$ as compared with the control in a mixture of hexane:ethanol:acetone (50:25:25). Further increments of electric field from 5 to $7 \mathrm{kV} / \mathrm{cm}$ did not increase significantly the extraction of carotenoids. The presence of acetone in the solvent mixture did not positively affect the carotenoid extraction when the tomato peels were PEF-treated. Response surface methodology was used to determine the potential of PEF for reducing the percentage of hexane in a hexane:ethanol mixture. The application of a PEF treatment allowed reducing the hexane percentage from 45 to $30 \%$ without affecting the carotenoid extraction yield. The antioxidant capacity of the extracts obtained from tomato peel was correlated with the carotenoid concentration and it was not affected by the PEF treatment.

Keywords: carotenoids, extraction, tomato, PEF, by-product

\section{INTRODUCTION}

The tomato is one of the most widely cultivated vegetable crops. Millions of tomato tons are processed every year to produce products such as ketchup and sauce, resulting in large amounts of by-products, such as peel, pulp, and seeds that represent a 10$40 \%$ of total processed tomatoes. Around $70 \%$ of wet pomace consists of the skin and pulp that are lycopene-rich components of waste originate from tomato paste manufacturing (1). Therefore, the tomato and its processed food products are considered to be one of the best sources of lycopene. Lycopene is the principal carotenoid in tomato that causes the fruit's characteristically red color. This compound can represent approximately $80-90 \%$ of the total carotenoids in the tomato (2). Lycopene can be used as a coloring and antioxidant agent in the food industry, and it is also used as a nutraceutical because of, its high antioxidant activity, thus reducing the risk of atherosclerosis and coronary heart disease. Moreover, epidemiological studies have connected the intake of lycopene to a lower risk of the incidence of certain types of cancers (2). Therefore, extracting lycopene from tomato waste is a good alternative for the valorization of this by-product.

The extraction of carotenoids from vegetable sources is usually carried out by using organic solvents (e.g., hexane, acetone, chloroform, ethanol, etc.) because they are soluble in fat. A mixture of hexane with acetone and ethanol is often employed $(2,3)$. Also, supercritical fluids using non-organic solvents are suitable for the extraction of compounds that can easily become degraded by light, oxygen, and high temperatures like lycopene, but the solubility of these substances is still relatively low compared to their solubility in organic solvents. High pressures must be applied to obtain reasonable extraction from dried vegetable material, making it a costlier process (4). Consequently, from an industrial point of view, solvent extraction is the first option because of its simplicity and low costs. However, the process is very time consuming and requires large amounts of solvents according to the mass of the final products.

In the extraction of natural products, the use of solvents defines a major part of the environmental performance, cost, safety, and health issues of the process. Studies performed by Capello et al. (5) have shown that hexane and acetone have higher combined environment, health, and safety (EHS) risk scores than ethanol.

Improving and optimization of the existing process and innovation in process and procedures are solutions that have been suggested for the design of green and sustainable methods to extract of natural products (6). Hence, there is an increasing demand for extraction techniques that improve extraction yield with a shorter extraction time and reduced organic solvent consumption (7). The ability of several methods, such as enzymes or ultrasounds, to assist in the extraction of lycopene from the tomato has been evaluated by different authors (8-10). These techniques require the sample to be ground and on occasions dried before the extraction. Such operations may cause a loss of the lycopene content and an increase in the processing cost.

Pulsed electric fields (PEFs) assisted extraction has been shown to be a promising technology for improving the extraction of valuable compounds from soft fresh vegetable materials (11). The process is based on the application of external electric fields 
that induce the electroporation of cytoplasmic membranes, thus enhancing the diffusion of solutes located inside the cells. This permeabilization of cell membranes can be achieved at moderate electric fields $(<10 \mathrm{kV} / \mathrm{cm})$ and low specific energies $(<10 \mathrm{~kJ} / \mathrm{kg})$.

An enhancement in the extraction of hydrophilic compounds such as sugar from the sugar beet, betaine from the red bet, and anthocyanins from grapes, red cabbage, or purple fleshed potatoes (12-14) through the application of a PEF treatment has been reported. However, the efficacy of PEF in improving the extraction of fat-soluble compounds has scarcely been investigated (15).

The key advantages of PEF-assisted extraction are that it is a non-thermal treatment that does not affect the quality of the extracted products, and the fact that it is possible to apply the treatments in a continuous flow, both at pilot plant and on an industrial scale, to fresh material (16).

In this investigation, it was studied the influence of the application of PEFs of different intensities $(3-7 \mathrm{kV} / \mathrm{cm}$ and $0-300 \mu \mathrm{s})$ on the carotenoid extraction from tomato peel and pulp in a mixture of hexane:acetone:ethanol with the aim of increasing extraction yield or reducing the percentage of solvents with a higher EHS. Response surface methodology (RSM) was used to determine the potential of PEF for reducing the percentage of hexane in a hexane:ethanol mixture without affecting the carotenoid extraction yield (CEY) and the antioxidant capacity of the extracts.

\section{MATERIALS AND METHODS PLANT MATERIAL}

Red tomatoes (commercial variety: tomate canario) were purchased from a local supermarket and stored at $4^{\circ} \mathrm{C}$ until required. Color measurements were performed on the surface of the tomatoes, at least four times, with a Minolta Chroma Meter CR-200 (Minolta Camera Co., Ltd., Osaka, Japan) tristimulus color analyzer. The readings were obtained in the CIE $\mathrm{L}^{\star} \mathrm{a}^{\star} \mathrm{b}^{\star}$ color space and the coordinates $\mathrm{L}^{*}, \mathrm{a}^{\star}$, and $\mathrm{b}^{*}$ were obtained by using the D65 standard observer and a visual angle of $10^{\circ}$. Tomatoes with similar coordinates were selected in order to use fruit that exhibited a homogeneous carotenoid concentration (17). Tomatoes were hand peeled. The resulting peel was cut in pieces with a diameter of $24 \mathrm{~mm}$; the pulp was cut into pieces with a diameter of $15 \mathrm{~mm}$.

\section{CHEMICALS}

Analytical-grade hexane and ethanol, analytical grade, were purchased from VWR International (Fontenay-sous-Bois, France). All solvents for HPLC analysis (acetonitrile, hexane, and methanol) were of a HPLC gradient grade and were obtained from Fisher Scientific (Fair Lawn, NJ, USA). All-trans-lycopene was purchased from Sigma Chemical Co. (Sigma-Aldrich Company, St. Louis, MO, USA).

\section{PEF TREATMENT}

The PEF equipment that was used in this investigation was supplied by ScandiNova (Modulator PG, ScandiNova, Uppsala, Sweden). The apparatus generates square waveform pulses of a width of $3 \mu \mathrm{s}$ with a frequency of up to $300 \mathrm{~Hz}$. The maximum output voltage and current were $30 \mathrm{kV}$ and $200 \mathrm{~A}$, respectively. The equipment consists of a direct current power supply, which converts the 3-phase line voltage to a regulated DC voltage. It charges up 6
IGBT switching modules (high-power solid-state switches) to a primary voltage around $1000 \mathrm{~V}$. An external trigger pulse gates all the modules and controls its discharge to a primary pulsed signal of around $1000 \mathrm{~V}$. Finally, a pulse transformer converts this primary $1000 \mathrm{~V}$ pulse to the desired high-voltage pulse.

The treatment chambers consisted of a cylindrical methacrylate tube closed with two polished stainless steel cylinders. Two different size chambers were used in this study due to the differences in the conductivity of peel and pulp. In order to treat the peel, a chamber with an electrode diameter of $24 \mathrm{~mm}$ and a gap of $5 \mathrm{~mm}$ was used. For the pulp treatment, the electrode diameter was $15 \mathrm{~mm}$ and the gap was $10 \mathrm{~mm}$.

The actual voltage and current intensity that were applied were measured with a high-voltage probe (Tektronix, P6015A, Wilsonville, OR, USA) and a current probe (Stangenes Industries, Inc., Palo Alto, CA, USA), respectively that were connected to an oscilloscope (Tektronix, TDS 220, Wilsonville, OR, USA).

The PEF treatments that ranged from 5 to 100 pulses of $3 \mu \mathrm{s}$ (45-300 $\mu \mathrm{s})$, set at electric field strength ranging from 3 to $7 \mathrm{kV} / \mathrm{cm}$ were used. The specific energy of these treatments ranged from 0.54 to $13.50 \mathrm{~kJ} / \mathrm{kg}$. A pulse frequency of $1 \mathrm{~Hz}$ was used.

\section{CELL DISINTEGRATION INDEX}

The cell disintegration index $\left(Z_{p}\right)$ was used to identify the PEF treatment conditions for the pre-treatment of the tomato peel or pulp before the carotenoid extraction. This index characterizes the proportion of permeabilized cells based on the frequency dependence of conductivity of intact and permeabilized plant tissues (18).

The cell disintegration index analysis was carried out by using impedance measurement equipment (DIL, Quakenbrück, Germany). For the experiments, untreated and PEF-treated disks of tomato peel or pulp were placed in the measuring cell of the equipment. $Z_{p}$ was calculated by using the following equation:

$$
Z_{p}=1-\left(\frac{K_{h}}{K_{h}^{\prime}}\right) \cdot \frac{\left(K_{h}^{\prime}-K_{l}^{\prime}\right)}{\left(K_{h}-K_{l}\right)} ; 0 \leq Z_{p} \leq 1
$$

where $K_{1}, K_{l}^{\prime}$ are the electrical conductivities of untreated and PEF-treated material, respectively, at a low-frequency field $(1-5 \mathrm{kHz}) ; K_{h}, K_{h}^{\prime}$ are the electrical conductivities of untreated and PEF-treated material, respectively, at a high-frequency field (3-50 MHz). The $Z_{p}$ varies between 0 for intact tissues and 1 for a tissue with all the cells permeabilized.

\section{CAROTENOID EXTRACTION}

Carotenoids were extracted by using different organic solvents and solvent mixtures. The polar solvents that were used consisted of acetone and ethanol, while the non-polar solvent that was used was hexane. A mixture of hexane:acetone:ethanol [50:25:25 (v:v:v)] was used in order to establish the intensity of the electric field strength to obtain the highest extraction. The first series of experiments were conducted with single solvents or mixtures of equal volumes (50:50) at a solvent to waste ratio of 20:1 (v:w). The second series of experiments were conducted with three mixtures of hexane and ethanol 25:75, 50:50, and 75:25 (v:v). 
Six disks $(5.0 \pm 0.5 \mathrm{~g})$ of the untreated and PEF-treated tomato peel, or four disks $(5.0 \pm 0.5 \mathrm{~g})$ of the untreated and PEF-treated tomato pulp were put in a $250 \mathrm{~mL}$ Erlenmeyer flask that contained $100 \mathrm{~mL}$ of the solvent. The flasks were incubated at $25^{\circ} \mathrm{C}$ in a water bath and shaken at $120 \mathrm{rpm}$. Samples of $1 \mathrm{~mL}$ of the extraction solvent were removed at different extraction times $(10,20,40,60,90$, $120,150,180,210,240,270$, and $300 \mathrm{~min}$ ).

\section{CAROTENOID QUANTIFICATION}

The extracts that were obtained at different points in time were centrifuged at $5,400 \times g$ for $6 \mathrm{~min}$ to separate the supernatant. When hexane was one of the components of the mixture of solvents that were used for extraction, the presence of water in the sample permitted to separate the extracting solution into poorly differentiated polar and non-polar layers. Adding $0.1 \mathrm{~mL}$ of water to $1 \mathrm{~mL}$ of the supernatant caused a complete separation into distinct polar and non-polar layers. The absorbance of the non-polar layer (i.e., the hexane layer) containing lycopene was measured at $472 \mathrm{~nm}$ on a spectrophotometer (Jenway 6505 UV/VIS, Jenway, Felsted, UK). Absolute hexane was used as blank. The amount of carotenoids was determined by using the molar extinction coefficient of lycopene in hexane at $472 \mathrm{~nm}$ (E1\% $1 \mathrm{~cm} \mathrm{3450)} \mathrm{(19)} \mathrm{and}$ expressed as milligram of carotenoids/100 g of fresh weight (FW) tomato peel or pulp.

\section{HPLC ANALYSIS OF CAROTENOIDS}

Before the HPLC analysis, the extracts were concentrated on a miVac concentrator (GeneVac Ltd., UK) for $15 \mathrm{~min}$ at $30^{\circ} \mathrm{C}$ by vacuum evaporation of $10 \mathrm{~mL}$ of the hexane and re-dissolved in $2 \mathrm{~mL}$ of hexane.

HPLC/DAD analyses were performed on a Varian ProStar high performance liquid chromatograph (Varian Inc., Walnut Creek, CA, USA) that was equipped with a ProStar 240 ternary pump, a ProStar 410 AutoSampler, and a ProStar 335 photodiode array detector. The system was controlled with a Star chromatography workstation v.6.41 (Varian). A reversed-phase column MicrosorbMV 100-5 C18 $(25 \mathrm{~cm} \times 0.46 \mathrm{~cm} ; 5 \mu \mathrm{m}$ particle size $)$ with a precolumn $(5 \mathrm{~cm} \times 0.46 \mathrm{~cm} ; 5 \mu \mathrm{m}$ particle size $)$ of the same material was used. The temperature of the column and the precolumn was maintained at $30^{\circ} \mathrm{C}$.

A linear gradient that consisted of acetonitrile (A), hexane (B), and methanol (C) was used as follows: $70 \% \mathrm{~A}, 7 \% \mathrm{~B}$, and $23 \% \mathrm{C}$ to $70 \% \mathrm{~A}, 4 \% \mathrm{~B}$, and $26 \% \mathrm{C}$ within $10 \mathrm{~min}$. The flow rate through the column was $1.5 \mathrm{~mL} / \mathrm{min}$, the sample injection was $10 \mu \mathrm{L}$, and the absorbance detection wavelength was $472 \mathrm{~nm}$. Prior to injection, all of the samples were filtered through a $0.2 \mu \mathrm{m}$ sterile syringe filter of cellulose acetate (VWR, West Chester, PA, USA).

Lycopene was identified by comparing their retention time and visible absorption spectra with this of its standard. Lutein and $\beta$-carotene were identified according to their retention time and characteristic absorption spectra found in bibliography (20-22).

\section{ANTIOXIDANT CAPACITY}

The antioxidant activity of the extracts was measured by using the modified ABTS [2,2' azinobis (3-ethylbenzothiazoline-6-sulfonic acid) diammonium salt] radical decolorization assay (23). The ABTS radical was generated by adding $2 \mathrm{~g}$ of $\mathrm{MnO}_{2}$ into $100 \mathrm{~mL}$ of $5 \mathrm{~mL}$ ABTS solution, stirred for $20 \mathrm{~min}$ at room temperature and filtered through a 0.2 PTFE syringe filter. On the day of analysis, the ABTS solution was diluted with ethanol (96\%) to an absorbance of $0.700 \pm 0.02$ at $734 \mathrm{~nm}$. Then $100 \mu \mathrm{L}$ of the extract was added to $1 \mathrm{~mL}$ of the ABTS radical solution and vortexed for $10 \mathrm{~s}$. One minute after the addition of the sample, the decolourization that was caused by reduction of the cations by antioxidants from the sample was measured spectrophotometrically at $734 \mathrm{~nm}$ (Jenway 6505 UV/VIS, Jenway, Felsted, UK). Assays were performed in triplicate. Trolox ${ }^{\circledR}$ (6 hydroxy-2,5,7,8trimethyl-chroman-2-carboxylic acid), a water-soluble vitamin $\mathrm{E}$ analog, was used to prepare the standard curve and the antioxidant activity was reported as micrograms of Trolox equivalent antioxidant.

\section{EXPERIMENTAL DESIGN}

Response surface methodology was used to determine optimal PEF-assisted extraction of carotenoids from tomato peel with respect to the hexane percentage in a hexane:ethanol solvent mixture and extraction time. Preliminary experiments indicated that an electric field of $5 \mathrm{kV} / \mathrm{cm}$ and treatment time of $90 \mu \mathrm{s}$ were the optimal PEF treatment conditions. Therefore, these PEF treatment conditions were selected to compare the CEY from untreated and PEF-treated tomato peel. A central composite design (CCD) was constructed to investigate the effects of hexane:ethanol solvent (from 25 to $75 \%$ of hexane) and extraction time (from 0 to $300 \mathrm{~min}$ ) on CEY. The obtained data were modeled with the following second-order polynomial equation:

$$
Y=\beta_{0}+\sum_{i=1}^{k} \beta_{i} X_{i}+\sum_{i=1}^{k} \beta_{i i} X_{i}^{2}+\sum_{i>j}^{k} \beta_{i j} X_{i} X_{j}
$$

where $Y$ is the response variable to be modeled, $X_{i}$ and $X_{j}$ are independent factors, $\beta_{0}$ is the intercept, $\beta_{i}$ is the linear coefficients, $\beta_{i j}$ is the quadratic coefficients, $\beta_{i j}$ is the cross-product coefficients, and $k$ is the total number of independent factors. A backward regression procedure was used to determine the parameters of the models. This procedure systematically removed the effects that were not significantly associated $(p>0.05)$ with the response until a model with only a significant effect was obtained.

The CCD and the corresponding analysis of the data were carried out by using the software package Design-Expert 6.0.6 (Stat-Ease Inc., Minneapolis, MN, USA).

\section{STATISTICAL ANALYSIS}

Experiments were performed in triplicate and the presented results are means \pm SD. One-way analysis of variance (ANOVA) using Tukey's test was performed to evaluate the significance of differences between the means values. The differences were considered significant at $p<0.05$. GraphPad PRISM (GraphPad Software, San Diego, CA, USA) was used to perform the statistical analysis.

\section{RESULTS AND DISCUSSION CHARACTERIZATION OF THE PEF INDUCED DAMAGE IN CELLS OF TOMATO PEEL}

The $Z_{p}$ was used to select the optimum PEF treatment conditions to permeabilize the cells of the tomato peel and pulp. This 
index, which is based on the changes of conductivity of intact and PEF permeabilization tissue, has been used by different authors in different vegetable tissues for this purpose (24). Figure 1 shows the influence of the treatment time on the $Z_{p}$ of tomato peel (Figure 1A) and pulp (Figure 1B) at different electric field strengths.

The general trend on the influence of the electric field strength and treatment time on the $Z_{p}$ value that was observed in this research supports previously reported data for other vegetable tissues such as potato, apple, onion, or orange $(18,25,26)$.

The increase in electric field strength and treatment time resulted in an increment of the $Z_{p}$ to a highest value of around 0.7 for the pulp and 0.3 for the peel. These results indicate that higher electric field strengths are required to permeabilization tomato peel cells than pulp cells. These noticeable differences to the electroporation effect between both tissues could be related to the cell size. As the transmembrane potential induced by PEF is proportional to the cell radius, lower electric field strength is required to induce the electroporation of pulp cells because they are bigger than peel cells (27).

Although the effect of the electric field strength on $Z_{p}$ was different for both tissues, in both cases the $Z_{p}$ value significantly increased with the treatment time up to $90 \mu \mathrm{s}$ ( 30 pulses of $3 \mu \mathrm{s}$ ), independent of the electric field strength that was applied. Further increments of the treatment time barely affected to the $Z_{p}$ value. According to these results, in additional studies that aimed to investigate the influence of electric field strength on the extraction of carotenoids, the treatment time was set at $90 \mu \mathrm{s}$.

\section{CHARACTERIZATION OF THE PEF TREATMENT IN THE EXTRACTION OF LYCOPENE FROM TOMATO PEEL}

A mixture of hexane with acetone and ethanol has been used by different authors to extract carotenoids from tomatoes and tomato products $(2,28,29)$. The effect of the application of PEF treatments on improving the extraction of carotenoids from tomato peel and pulp was tested in this solvent mixture. Figure 2 shows the influence of a PEF treatment application at different electric field strengths $(3,5$, and $7 \mathrm{kV} / \mathrm{cm}$ for $90 \mu \mathrm{s})$ on the extraction of carotenoids from peel (Figure 2A) and pulp (Figure 2B) through the time.

The results obtained in this investigation confirm the observations of other authors who have reported that tomato skin contained significantly higher amounts of lycopene than tomato pulp (30). Moreover, while the extraction of lycopene from the peel increased with the intensity of the electric field strength that was applied, the application of PEF treatments of different intensities to the pulp did not significantly increase the lycopene extraction as in comparison to the untreated sample. Therefore, the permeabilization of the cells of the pulp by PEF did not affect either the capacity of penetration of the solvent into the cells or the diffusion of carotenoids through the cytoplasmic membrane, resulting in a similar extraction from both intact and permeabilized cells. For this reason, no further experiments were made with this matrix.

On the contrary, it can be observed that the extraction of carotenoids from tomato peels was significantly improved by the application of the PEF treatment. This increment was augmented by increasing the electric field strength up to $5 \mathrm{kV} / \mathrm{cm}$. However, an increase in the intensity of the electric field strength up to $7 \mathrm{kV} / \mathrm{cm}$ did not involve any further rise in the CEY. After $200 \mathrm{~min}$, the extraction of carotenoids from tomato peels improved 13 and $39 \%$ in comparison to the control when the peels had been PEFtreated with 3 and $5 \mathrm{kV} / \mathrm{cm}$, respectively. Therefore, the electric field strength of $5 \mathrm{kV} / \mathrm{cm}$ was set for further experimentations.

The increase in the carotenoids extraction yield can be explained by the electroporation effect caused by PEF on the cytoplasmic membrane of tomato peel cells. The increment of the
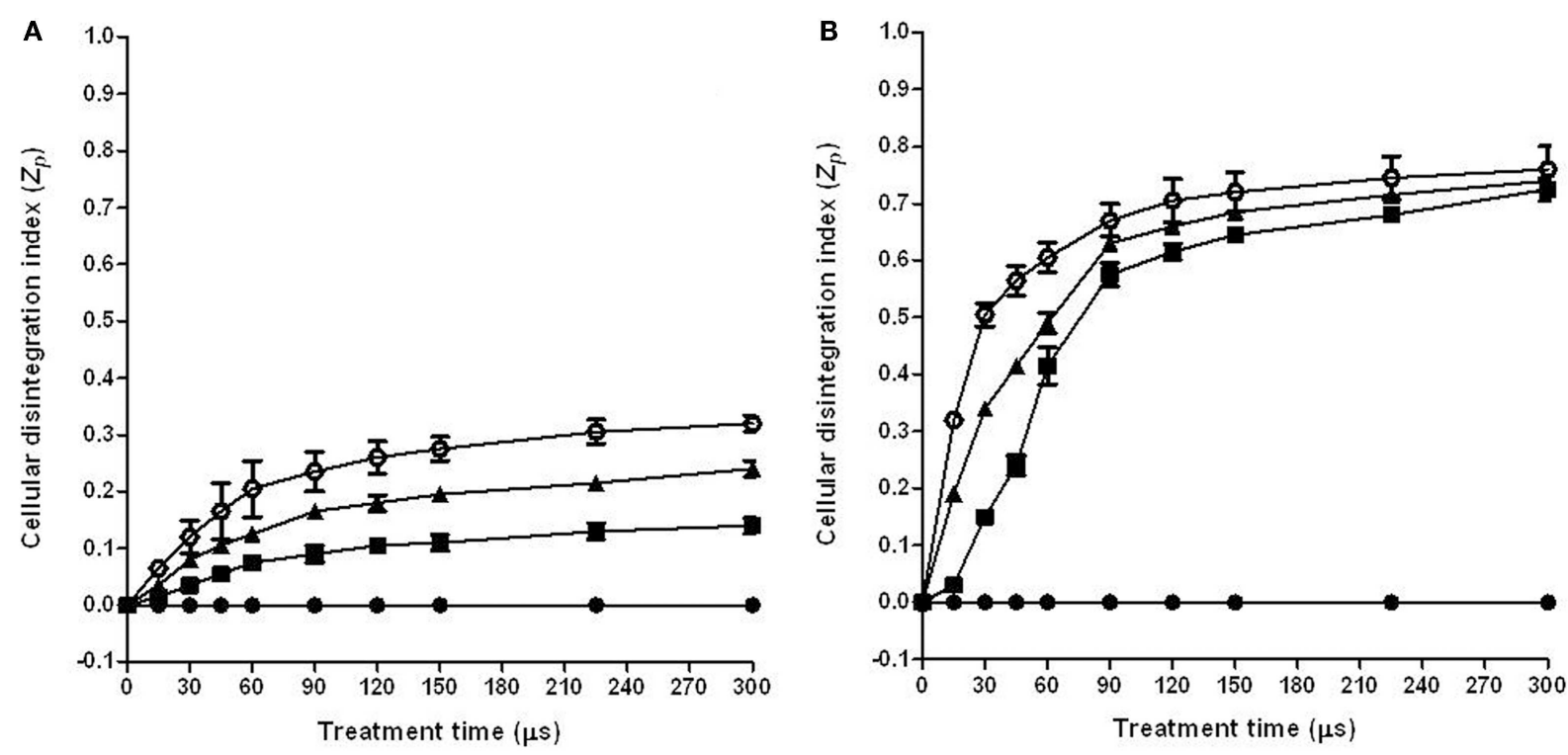

FIGURE 1 | Influence of electric field strength and treatment time on the cell disintegration index $\left(Z_{p}\right)$ of tomato peel (A) and pulp (B). $3 \mathrm{kV} / \mathrm{cm}$, ( $\mathbf{\Delta}) 5 \mathrm{kV} / \mathrm{cm},(\mathrm{O}) 7 \mathrm{kV} / \mathrm{cm}$. The error bars represent SEM. 

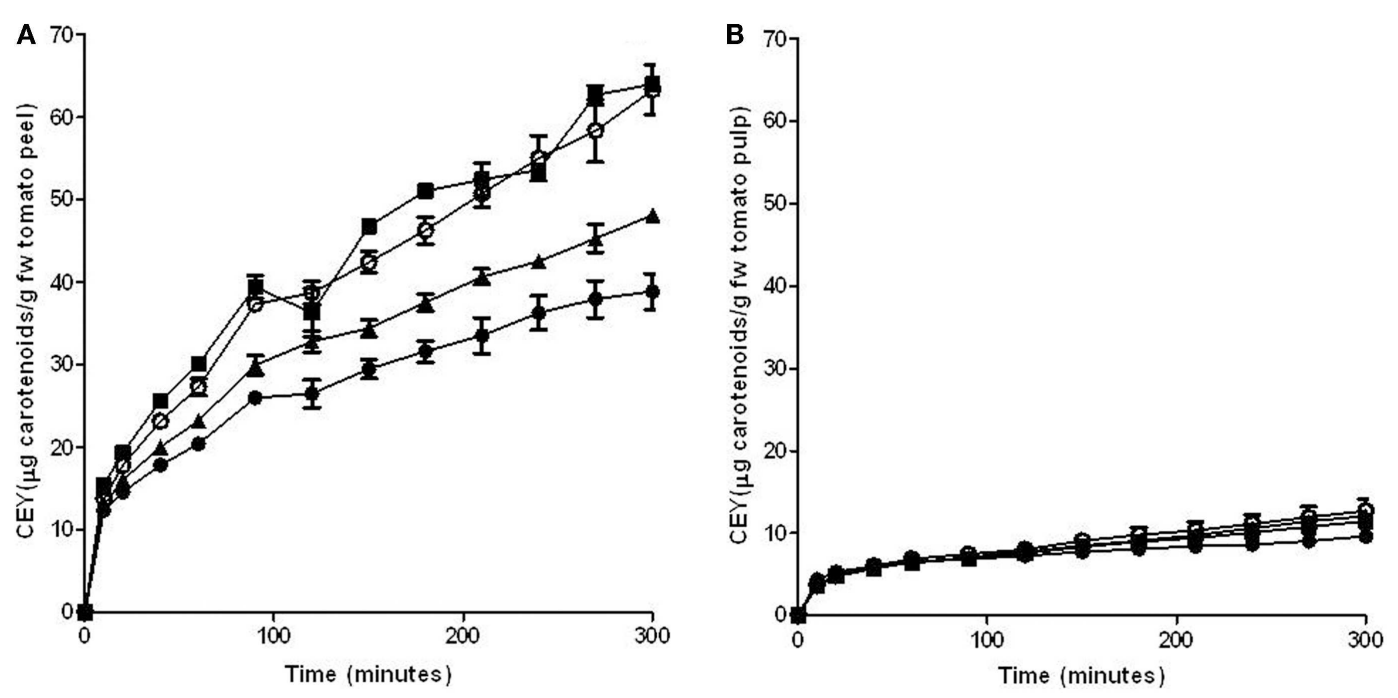

FIGURE 2 | Influence of electric field strength on the carotenoid extraction yield (CEY) from tomato peel (A) and pulp (B) using a mixture of hexane:acetone:ethanol (50:25:25) as extraction solvent. (O) Control, ( $\mathbf{\square}) 3 \mathrm{kV} / \mathrm{cm},(\boldsymbol{\Delta}) 5 \mathrm{kV} / \mathrm{cm}$, (O) $7 \mathrm{kV} / \mathrm{cm}$. The error bars represent SEM.

permeability of the cytoplasmic membrane that acts as a semipermeable barrier, facilitates the penetration of the solvents into the cells and the release of the carotenoids located inside the cells, and it increases the carotenoid extraction rate. For instance, the application of a PEF treatment at $5 \mathrm{kV} / \mathrm{cm}$ reduced the extraction time for obtaining the same amount of carotenoids $(690 \mu \mathrm{g} / 100 \mathrm{~g})$ in the untreated and PEF-treated samples from 200 to $85 \mathrm{~min}$.

\section{EFFECT OF THE PEF TREATMENT IN THE EXTRACTION OF LYCOPENE FROM TOMATO PEEL WITH DIFFERENT SOLVENTS}

Figure 3 compares the CEY for untreated and PEF-treated $(5 \mathrm{kV} / \mathrm{cm}, 90 \mu \mathrm{s})$ samples of tomato peel by using different individual, or mixture, of solvents after $300 \mathrm{~min}$ of extractions. The combination of hexane with ethanol or with ethanol and acetone improved the total yield in comparison to that obtained by any of the individual solvents. On the contrary, acetone alone presented a higher CEY than its mixture with hexane. The solubility capacity of solvents plays a very important role in the extraction process, even in the samples that were previously treated by PEF. Ethanol is a polar solvent that hardly solubilizes carotenoids, due to their lipophilicity. Nevertheless, the combination of ethanol and a nonpolar solvent such as hexane considerably improved the extraction of carotenoids. Therefore, the combination of ethanol with hexane shows a synergistic effect. In addition to the solubility, the capacity of penetration or diffusion of the solvents into the solid matrix also has an important role in the extraction efficiency. Acetone alone is a good solvent and a wetting material that penetrates easier in the solid matrix than the hexane:acetone mixture. In this case, the addition of hexane reduced the acetone capacity to penetrate into the cells, and the yield obtained by the mixture was lower than that of acetone in both untreated and PEF-treated samples. Similar results were obtained by Strati (31), who found that the acetone:hexane mixture was less efficient than acetone in extracting carotenoids from dry tomato waste, whereas Lin (32) found that the hexane:ethanol mixture was also more efficient than the hexane:acetone mixture in extracting carotenoids from tomato juice. The presence of water in the tomato juice and the higher solubility of ethanol than acetone in water could explain this fact. The importance of solvent solubility in water, when extraction is conducted in a fresh matrix, was demonstrated by the lack of extraction of carotenoids in both untreated and PEF-treated samples when hexane was used as solvent (results not shown).

The application of a PEF treatment to the tomato peels before extraction involved an increase of the CEY when the extraction was made with acetone, hexane:ethanol (50:50), or hexane:acetone:ethanol (50:25:25), whereas no significant effect of the PEF treatment was observed when the extraction was made with hexane:acetone (50:50) or ethanol. Therefore, although the permeabilization of the tomato peel cells has been demonstrated (Figure 1), the use of solvents with enough solubility and penetration capacity is necessary to observe an improvement in the CEY in comparison to the control.

The highest carotenoid yield ( 38 and $58 \mu \mathrm{g} / \mathrm{g}$ of FW tomato peel from untreated and PEF-treated tomato peel, respectively) was obtained when carotenoids were extracted with a mixture of hexane:acetone:ethanol (50:25:25). However, no significant differences $(p>0.05)$ were observed between the extraction with this mixture and the hexane:ethanol mixture when a PEF treatment was applied prior to extraction. As (EHS) risk scores for acetone are higher than those for ethanol in further experiments, acetone was removed from the solvent mixture and the optimization of the hexane and ethanol mixture was carried out.

\section{OPTIMIZATION OF SOLVENT CONTENT IN THE MIXTURE HEXANE:ETHANOL FOR PEF-ASSISTED EXTRACTION OF CAROTENOIDS} The CEY resulting from the three different proportions of hexane:ethanol $(25: 75,50: 50,75: 25)$ at different extraction times $(20,160,300 \mathrm{~min})$ for the control (untreated) and the PEF-treated 


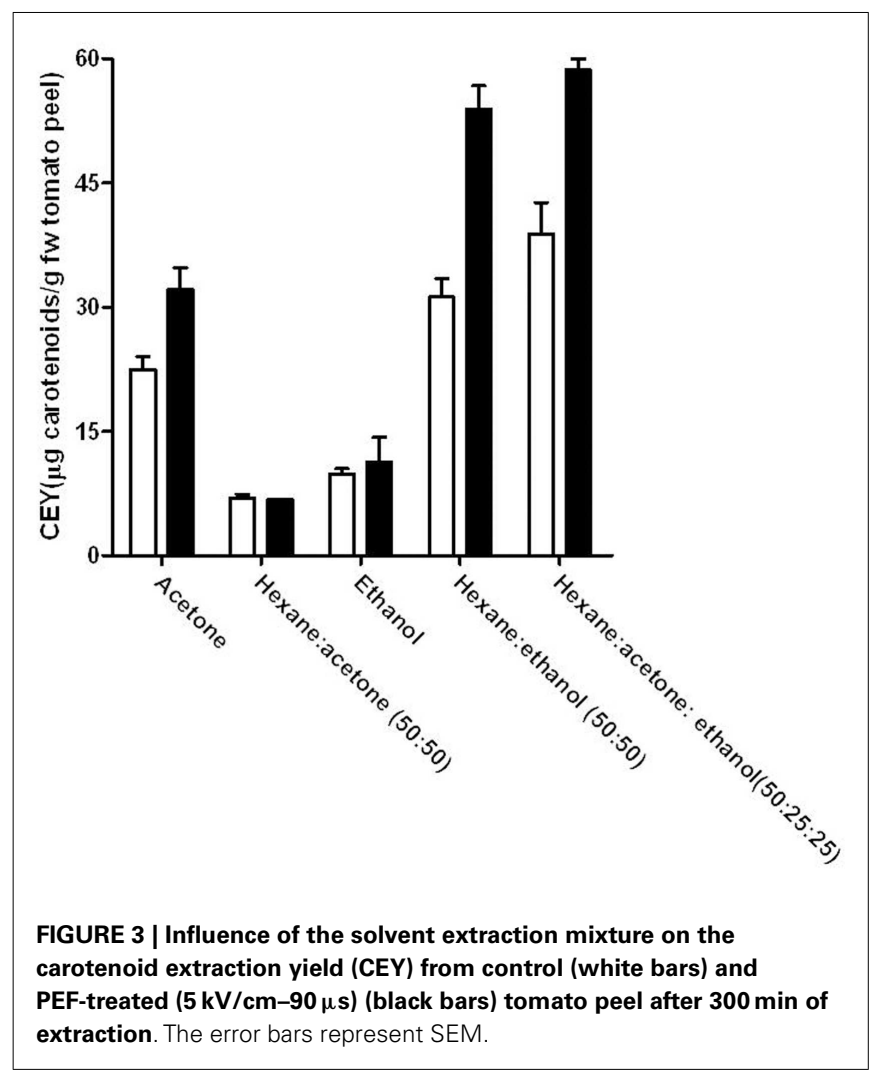

Table 1 | Effect of percentage of hexane and extraction time on the carotenoid extraction yield (CEY) from tomato peel non-treated (control) and PEF-treated.

\begin{tabular}{lccc}
\hline Hexane (\%) & Time $(\mathbf{m i n})$ & \multicolumn{2}{c}{ CEY $(\boldsymbol{\mu} \mathbf{g} / \mathbf{g}$ FW tomato peel) } \\
\cline { 3 - 4 } & & Control & PEF-treated \\
\hline 25 & 20 & $11.80 \pm 0.65$ & $12.29 \pm 0.20$ \\
& 160 & $24.21 \pm 0.89$ & $27.87 \pm 2.05^{\mathrm{a}}$ \\
& 300 & $31.61 \pm 1.32$ & $39.00 \pm 0.92^{\mathrm{a}}$ \\
50 & 20 & $18.24 \pm 3.53$ & $19.54 \pm 3.27$ \\
& 160 & $30.01 \pm 3.02$ & $40.85 \pm 7.23^{\mathrm{a}}$ \\
75 & 300 & $44.14 \pm 4.00$ & $58.81 \pm 9.44^{\mathrm{a}}$ \\
& 20 & $6.78 \pm 0.48$ & $6.48 \pm 0.53$ \\
& 160 & $9.43 \pm 0.61$ & $11.80 \pm 1.43$ \\
& 300 & $11.54 \pm 0.15$ & $15.62 \pm 0.89^{\mathrm{a}}$ \\
\end{tabular}

The results are expressed as mean \pm CL (95\%).

a Significantly differences $(p<0.05)$ between the extraction from control and PEF-treated peels.

tomato peels are shown in Table 1. The experimental values of CEY there were obtained varied from 6.48 to $58.81 \mu \mathrm{g} / \mathrm{g}$ FW tomato peel. These contents are within the range of the values that are reported in the literature by other authors who have investigated the extraction of carotenoids from fresh tomato waste in different solvents and solvent mixtures at distinct temperatures $(29,33,34)$.
Table $2 \mid \boldsymbol{F}$-value and $\boldsymbol{p}$-value of significant variables and their interaction of the polynomial equation describing the influence of the percentage of hexane and extraction time on the carotenoid extraction yield (CEY) from tomato peel non-treated (control) and PEF-treated

\begin{tabular}{llrllrl}
\hline & \multicolumn{3}{c}{ Control } & \multicolumn{3}{c}{ PEF } \\
\cline { 2 - 6 } & $\begin{array}{l}\text { Coeffi- } \\
\text { cient }\end{array}$ & F-value & $\boldsymbol{p}$-Value & $\begin{array}{l}\text { Coeffi- } \\
\text { cient }\end{array}$ & F-value & $\boldsymbol{p}$-Value \\
\hline Intercept & -25.71 & & & -44.71 & & \\
$H$ & +2.156 & 16.43 & 0.0098 & 3.15 & 9.75 & 0.0168 \\
$t$ & +0.0606 & 10.07 & 0.0247 & +0.089 & 26.59 & 0.0013 \\
$H^{2}$ & -0.0242 & 17.39 & 0.0087 & -0.034 & 36.22 & 0.0005 \\
Model & & 14.63 & 0.0066 & & 29.93 & 0.0005 \\
$R^{2}$ & & 0.89 & & & 0.91 & \\
$R^{2}$-adj & & 0.83 & & & 0.87 & \\
RMSE & & 0.00 & & & 0. & \\
Lack of fit & & 26.37 & & & 49.05 & \\
\hline
\end{tabular}

The permeabilization of the tomato peel by PEF prior to the extraction process did not significantly increase the CEY $(p>0.05)$ in the first extraction times. However, for longer extraction times, the CEY improved until it reached approximately $30 \%$ in comparison to the control by the application of the PEF treatment.

In order to optimize the hexane percentage and extraction time required for the extraction of carotenoids from tomato peel treated by PEF, a multiple regression analysis was performed according to the experimental data shown in Table 1 . The analysis resulted in second-order polynomial equations for both untreated and PEF-treated samples after removing the non-significant terms $(p>0.05)$. Figure 4 shows the response surface graphs obtained with these polynomial equations. Table 2 indicates the coefficients and $F$-values for significant variables and their interactions for equations describing the relationship between the CEY, the percentage of hexane in the solvent and the extraction time for both untreated and PEF-treated samples. A summary of the ANOVA for the selected quadratic models is also shown in Table 2.

The determination coefficient for each model was higher than 0.90 , which means that $<10 \%$ of the total response variation remained unexplained by the models. The adjusted $R^{2}\left(R^{2}\right.$-adj) values, which correct the $R^{2}$ according to the sample size and the number of terms in the model (35), were similar to the corresponding $R^{2}$, indicating that there is good agreement between the experimental and predicted values. This statement was confirmed according to the root mean square error (RMSE) parameter, thus showing that all models produced predictions that were close to the observed data. The results of the $F$ test indicate that the predicted and observed values for the models are not significantly different. A non-significant lack of fit $F$-value $(p>0.05)$ was observed, indicating that the variation between samples was due only to the factors selected for the model and the pure error. The $F$-values for model parameters are very useful as indicators of the significance of the effects of the variables and their interactions. In both PEF-treated and the untreated samples, the most significant effect 

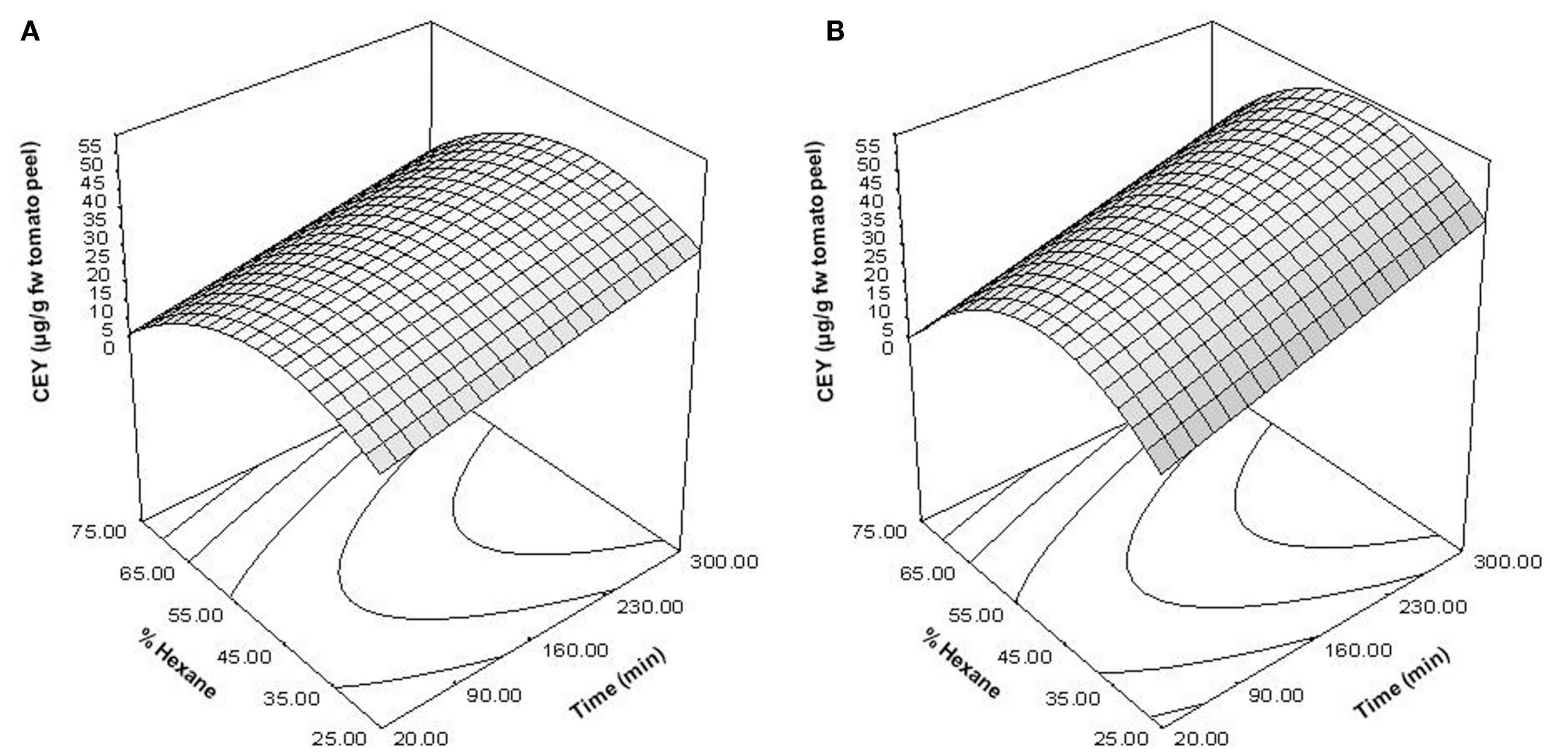

FIGURE 4 | Response surface plots showing the influence of the percentage of hexane and extraction time on the carotenoid extraction yield (CEY) expressed as microgram of carotenoids per gram of fresh weight (FW) tomato peel. Control (A); PEF-treated (B).

on extraction was the quadratic term of the proportion of hexane $\left(\mathrm{H}^{2}\right)$, followed by time. This means that changes in these factors will have the most significant effect on the carotenoid extraction. The significance of the squared factor $\left(\mathrm{H}^{2}\right)$ reveals the existence of an optimum hexane proportion for the highest CEY at $47 \%$ of hexane. Similar results were obtained by Strati (31), who achieved the maximum CEY with a solvent mixture at $45 \%$ of hexane.

On the other hand, these models enabled the estimation of the conditions (percentage of hexane and extracting time) to achieve a certain CEY from untreated and PEF-treated tomato peels. As an example, Figure 5 shows the combination of extraction time and percentage of hexane for obtaining several CEY from untreated and PEF-treated tomato peels in the investigated range. In this figure, it can be observed that the extraction improvement caused by PEF could allow one to reduce the hexane percentage after a given extraction time to get a fixed CEY. For instance, the percentage of hexane could be reduced from 45 to $30 \%$ when the extraction time was set at $150 \mathrm{~min}$ by applying a PEF treatment before extraction in order to achieve a CEY of $30 \mu \mathrm{g} / \mathrm{g}$ FW of tomato peel.

More noticeably, from this figure it can be pointed out that the application of PEF treatments would enable one to considerably decrease the extracting time considerably. For instance, the application of a PEF treatment to the tomato peels before extraction could reduce the extracting time more than six times (from 130 to $20 \mathrm{~min}$.) to extract $30 \mu \mathrm{g} / \mathrm{g} \mathrm{FW}$ with a $47 \%$ of hexane in comparison to the control.

\section{HPLC ANALYSIS OF THE MAIN CAROTENOID OBTAINED BY EXTRACTION FROM TOMATO PEELS TREATED BY PEF}

Reverse-phase HPLC chromatogram profiles detected at $472 \mathrm{~nm}$ for the extract of untreated and PEF-treated tomato peels were similar for both untreated and treated samples and only depended

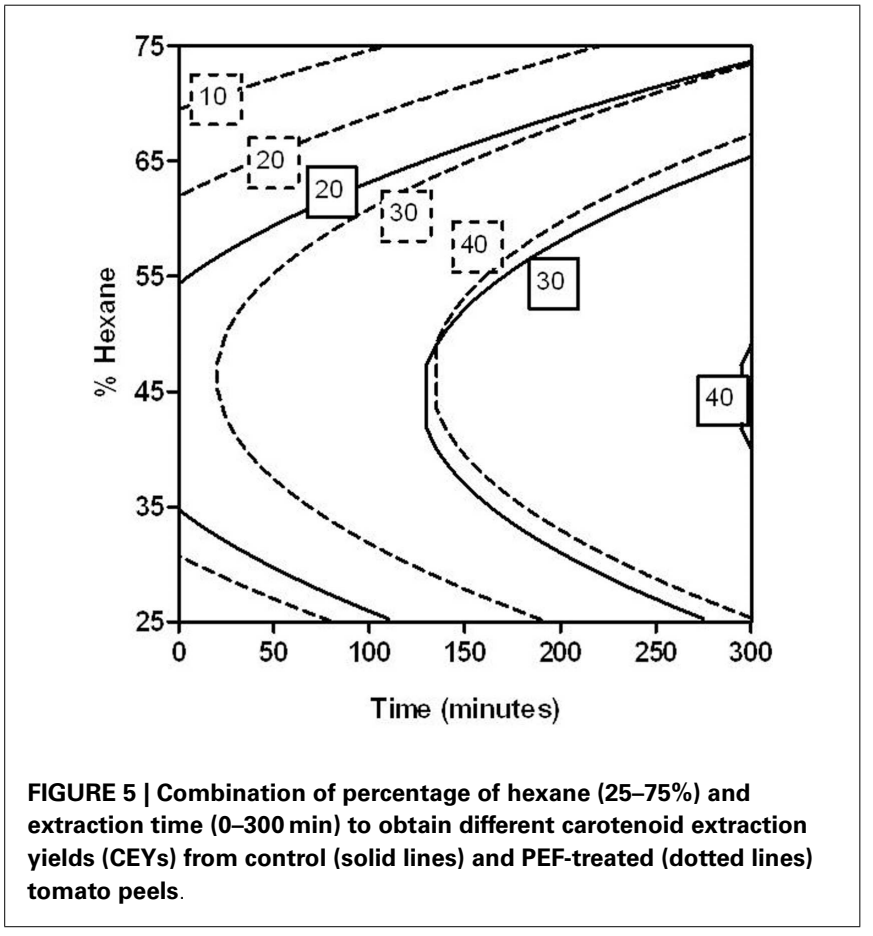

on the proportion of hexane in the solvent mixture (results not shown). In both untreated and PEF-treated samples, the percentage of individual carotenoids differed depending of the proportion of solvents used in the mixture. The lowest $(28 \%)$ and the highest percentages $(100 \%)$ for lycopene were observed in hexane $25 \%$ and hexane $75 \%$ extracts, respectively. On the other hand, lutein was only observed at proportions of around $18 \%$ when the proportion of hexane in the mixture was $25 \%$. 


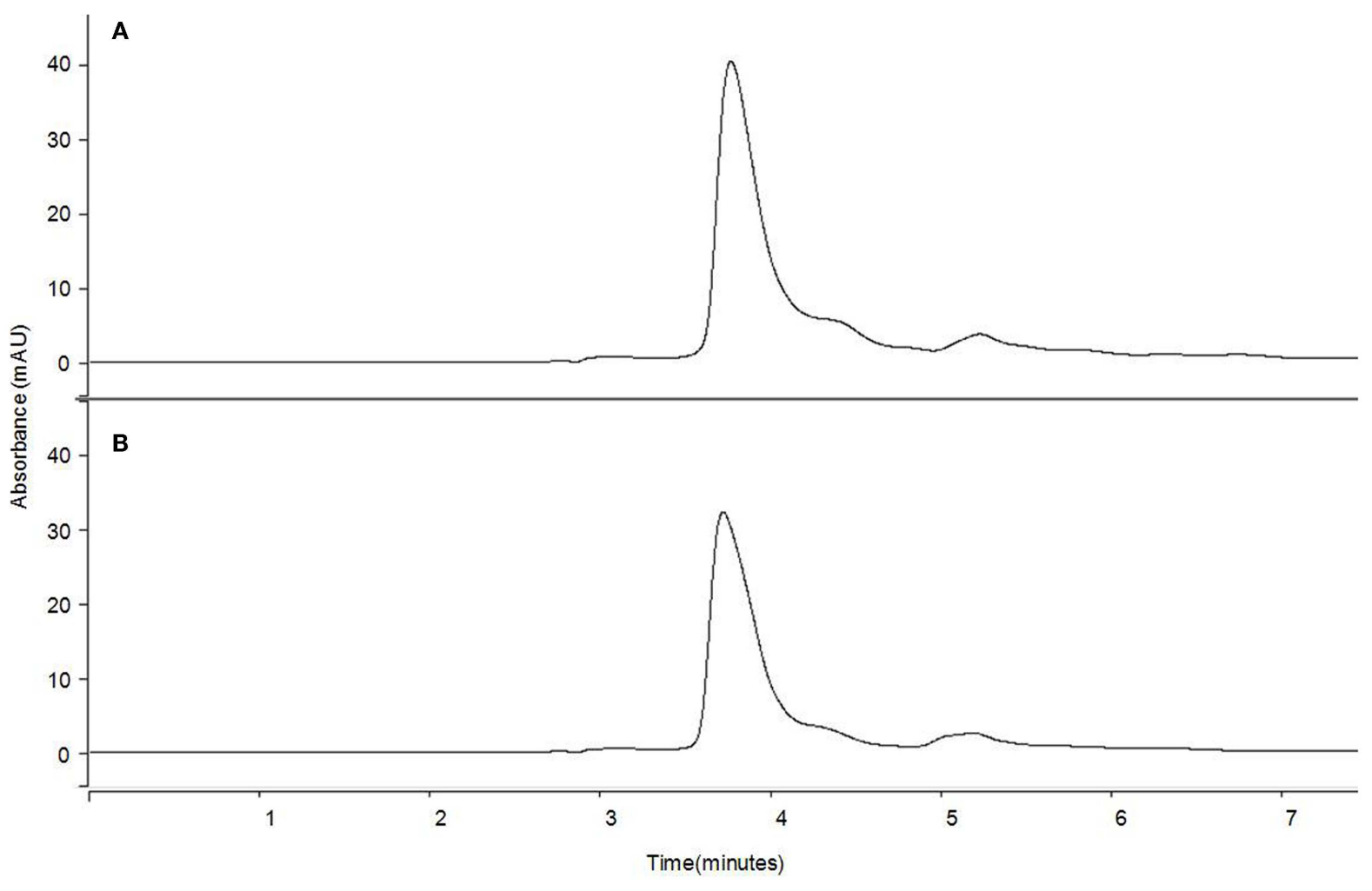

FIGURE 6 | HPLC chromatograms of carotenoid profiles of $50 \%$ hexane extract from tomato peel at $472 \mathrm{~nm}$ for (A) PEF-treated and (B) control sample

These results are consistent with the observation of Strati (31) and Hakala (36). Such findings could be related to the solubility of lutein in ethanol, which is 15-folds higher than the respective one in hexane. Similarly, the solubility of lycopene in ethanol is 20 -folds lower than in hexane (37).

Figure 6 compares as an example the HPLC chromatogram profiles at $472 \mathrm{~nm}$ for the extract obtained from untreated and PEF-treated tomato peels in a solvent with the same proportion of hexane and ethanol (50:50). The application of a PEF treatment to the tomato peel before extraction did not specifically affect the extraction of a certain carotenoid and no evidence of carotenoid degradation or isomerization by PEF treatments could be found. The only difference observed was that the peak areas were approximately $20 \%$ higher in the chromatograms that corresponded to the PEF-treated tomato peels. Similar results were obtained by other authors, who observed analogous chromatogram profiles of the control and PEF-treated samples, but with bigger peaks in the PEF-treated ones $(14,38,39)$.

\section{EFFECT OF ELECTRIC FIELD STRENGTH ON THE ANTIOXIDANT ACTIVITY OF TOMATO PEEL EXTRACT}

Beneficial implications of carotenoids in human health are due to their capacity to protect biomolecules against oxidation by quickly reducing reactive oxygen species including free radicals. The effect of PEF treatment on the antioxidant potential of the corresponding extracts was evaluated. As shown in Figure 7, the antioxidant activities of the extracts were related to the amount of extracted

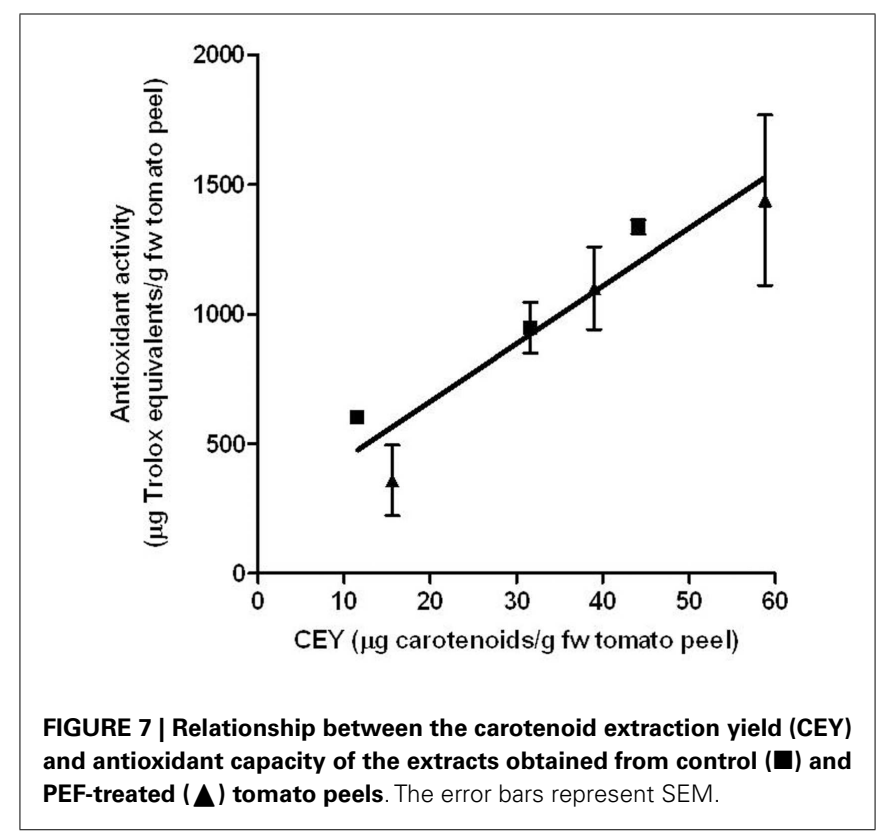

carotenoids. No statistically significant differences $(p>0.05)$ were observed in the antioxidant capacity of the carotenoids that were extracted from the control and the one extracted from the PEFtreated tomato peels. Therefore, PEF-assisted extracts had a higher antioxidant capacity than the control ones due to their higher 
carotenoid concentration. It has been observed that PEF application also increased the antioxidant activity of the grape by-product extracts; further, the apple juice that was extracted by pressing was approximately twofolds higher for the PEF-treated samples than in the control extraction $(12,40)$. This increment has also been related to the higher concentration of compounds with antioxidant activity in the extracts.

\section{CONCLUDING REMARKS}

Generally, the efficacy of PEF for improving the extraction of intracellular compounds has been assessed with water-soluble molecules. The results obtained in this investigation demonstrated that the electroporation of cytoplasmic membranes of tomato peels also increases the extraction of fat-soluble compounds such as carotenoids. The use of a mixture of polar and non-polar solvents results in the highest extraction yield for both untreated and PEFtreated samples. The application of a PEF pre-treatment to the tomato peels before extraction with a mixture of hexane:ethanol permitted an increase in the extraction time or the reduction of the proportion of hexane in the sample and extraction time without affecting the extraction yield.

\section{ACKNOWLEDGMENTS}

This research was supported by the Government of Aragón (Grupo de Investigación Consolidado A20), and the European Social Fund. Elisa Luengo gratefully acknowledges the financial support for her doctoral studies from the Department of Science, Technology and University of the Aragon Government.

\section{REFERENCES}

1. Kaur D, Wani AA, Oberoi DP, Sogi DS. Effect of extraction conditions on lycopene extractions from tomato processing waste skin using response surface methodology. Food Chem (2008) 108:711-8. doi:10.1016/j.foodchem. 2007.11.002

2. Shi J, Le Maguer M. Lycopene in tomatoes: chemical and physical properties affected by food processing. Crit Rev Food Sci Nutr (2000) 40:1-42. doi:10.1080/10408690091189275

3. van den Berg H, Faulks R, Granado HF, Hirschberg J, Olmedilla B, Sandmann $G$, et al. The potential for the improvement of carotenoid levels in foods and the likely systemic effects. J Sci Food Agric (2000) 80:880-912. doi:10.1002/(SICI) 1097-0010(20000515)80:7<880::AID-JSFA646>3.0.CO;2-1

4. Mattea F, Martin A, Jose Cocero M. Carotenoid processing with supercritical fluids. J Food Eng (2009) 93:255-65. doi:10.1016/j.jfoodeng.2009.01.030

5. Capello C, Fischer U, Hungerbuehler K. What is a green solvent? A comprehensive framework for the environmental assessment of solvents. Green Chem (2007) 9:927-34. doi:10.1039/b617536h

6. Chemat F, Vian MA, Cravotto G. Green extraction of natural products: concept and principles. Int J Mol Sci (2012) 13:8615-27. doi:10.3390/ijms13078615

7. Zhang HF, Yang XH, Wang Y. Microwave assisted extraction of secondary metabolites from plants: current status and future directions. Trends Food Sci Technol (2011) 22:672-88. doi:10.1016/j.tifs.2011.07.003

8. Choudhari SM, Ananthanarayan L. Enzyme aided extraction of lycopene from tomato tissues. Food Chem (2007) 102:77-81. doi:10.1016/j.foodchem. 2006.04.031

9. Lianfu Z, Zelong L. Optimization and comparison of ultrasound/microwave assisted extraction (UMAE) and ultrasonic assisted extraction (UAE) of lycopene from tomatoes. Ultrason Sonochem (2008) 15:731-7. doi:10.1016/j. ultsonch.2007.12.001

10. Eh AL, Teoh SG. Novel modified ultrasonication technique for the extraction of lycopene from tomatoes. Ultrason Sonochem (2012) 19:151-9. doi:10.1016/j. ultsonch.2011.05.019

11. Donsi F, Ferrari G, Pataro G. Applications of pulsed electric field treatments for the enhancement of mass transfer from vegetable tissue. Food Eng Rev (2010) 2:109-30. doi:10.1007/s12393-010-9015-3
12. Corrales M, Toepfl S, Butz P, Knorr D, Tauscher B. Extraction of anthocyanins from grape by-products assisted by ultrasonics, high hydrostatic pressure or pulsed electric fields: a comparison. Innov Food Sci Emerg Technol (2008) 9:85-91. doi:10.1016/j.ifset.2007.06.002

13. Gachovska T, Cassada D, Subbiah J, Hanna M, Thippareddi H, Snow D. Enhanced anthocyanin extraction from red cabbage using pulsed electric field processing. J Food Sci (2010) 75:E323-9. doi:10.1111/j.1750-3841.2010. 01699.x

14. Puertolas E, Cregenzan O, Luengo E, Alvarez I, Raso J. Pulsed-electric-fieldassisted extraction of anthocyanins from purple-fleshed potato. Food Chem (2013) 136:1330-6. doi:10.1016/j.foodchem.2012.09.080

15. Yin Y, Cui Y, Ding H. Optimization of betulin extraction process from Inonotus obliquus with pulsed electric fields. Innov Food Sci Emerg Technol (2008) 9:306-10. doi:10.1016/j.ifset.2007.07.010

16. Toepfl S, Heinz V. Pulsed electric field assisted extraction - a case study. In: Zhang HQ, Barbosa-Cánovas GV, Balasubramaniam VM, Dunne CP, Farkas DF, Yuan JTC, editors. Nonthermal Processing Technologies for Food. Wiley-Blackwell (2010). p. 190-200.

17. Arias R, Lee TC, Logendra L, Janes H. Correlation of lycopene measured by HPLC with the $L^{*}, a^{*} b^{*}$ color readings of a hydroponic tomato and the relationship of maturity with color and lycopene content. J Agric Food Chem (2000) 48:1697-702. doi:10.1021/jf990974e

18. Angersbach A, Heinz V, Knorr D. Electrophysiological model of intact and processed plant tissues: cell disintegration criteria. Biotechnol Prog (1999) 15:753-62. doi:10.1021/bp990079f

19. Davies BH. Carotenoids. In: Goodwin TW, editor. Chemistry and Biochemistry of Plant Pigments. London: Academic Press (1976). p. 38-155.

20. Barba AI, Hurtado MC, Mata MC, Ruiz VF, de Tejada ML. Application of a UV-vis detection-HPLC method for a rapid determination of lycopene and $\beta$ carotene in vegetables. Food Chem (2006) 95:328-36. doi:10.1016/j.foodchem. 2005.02.028

21. Dias MG, Oliveira L, Camoes MF, Nunes B, Versloot P, Hulshof PJ. Critical assessment of three high performance liquid chromatography analytical methods for food carotenoid quantification. J Chromatogr A (2010) 1217:3494-502. doi:10.1016/j.chroma.2010.03.024

22. Xu F, Yuan QP, Dong HR. Determination of lycopene and b-carotene by highperformance liquid chromatography using sudan I as internal standard. J Chromatogr B (2006) 838:44-9. doi:10.1016/j.jchromb.2006.04.004

23. Miller NJ, Rice-Evans CA. Factors influencing the antioxidant activity determined by the ABTS(center dot+) radical cation assay. Free Radic Res (1997) 26:195-9. doi:10.3109/10715769709097799

24. Vorobiev E, Lebovka N. Enhanced extraction from solid foods and biosuspensions by pulsed electrical energy. Food Eng Rev (2010) 2:95-108. doi:10.1007/ s12393-010-9021-5

25. Lebovka NI, Bazhal MI, Vorobiev E. Estimation of characteristic damage time of food materials in pulsed-electric fields. J Food Eng (2002) 54:337-46. doi:10.1016/S0260-8774(01)00220-5

26. Asavasanti S, Ersus S, Ristenpart W, Stroeve P, Barrett DM. Critical electric field strengths of onion tissues treated by pulsed electric fields. J Food Sci (2010) 75:E433-43. doi:10.1111/j.1750-3841.2010.01768.x

27. Zimmerma U, Pilwat G, Riemann F. Dielectric-breakdown of cell-membranes. Biophys J (1974) 14:881-99.

28. Sadler G, Davis J, Dezman D. Rapid extraction of lycopene and $\beta$-carotene from reconstituted tomato paste and pink grapefruit homogenates. J Food Sci (1990) 55:1460-1. doi:10.1111/j.1365-2621.1990.tb03958.x

29. Periago MJ, Rincon F, Jacob K, Garcia-Alonso J, Ros G. Detection of key factors in the extraction and quantification of lycopene from tomato and tomato products. J Agric Food Chem (2007) 55:8825-9. doi:10.1021/jf0705623

30. Markovic K, Krbavcic IP, Krpan M, Bicanic D, Vahcic N. The lycopene content in pulp and peel of five fresh tomato cultivars. Acta Aliment (2010) 39:90-8. doi:10.1556/AAlim.39.2010.1.9

31. Strati IF, Oreopoulou V. Process optimisation for recovery of carotenoids from tomato waste. Food Chem (2011) 129:747-52. doi:10.1016/j.foodchem. 2011.05.015

32. Lin $\mathrm{CH}$, Chen BH. Determination of carotenoids in tomato juice by liquid chromatography. J Chromatogr A (2003) 1012:103-9. doi:10.1016/S0021-9673(03) 01138-5

33. Toor RK, Savage GP. Antioxidant activity in different fractions of tomatoes. Food Res Int (2005) 38:487-94. doi:10.1016/j.foodres.2004.10.016 
34. Javanmardi J, Kubota C. Variation of lycopene, antioxidant activity, total soluble solids and weight loss of tomato during postharvest storage. Postharvest Biol Technol (2006) 41:151-5. doi:10.1016/j.postharvbio.2006.03.008

35. Frank JR. Experimental design in biotechnology, statistics: textbooks and monographs, volume 105 Perry D. Haaland Marcel Dekker, Inc., New York, NY, 259 pages [ISBN No.: 0-8247-7881-2] U.S. (1989). Environ Prog (1992) 11:A8-9. doi:10.1002/ep.670110307

36. Hakala SH, Heinonen IM. Chromatographic purification of natural lycopene. J Agric Food Chem (1994) 42:1314-6. doi:10.1021/jf00042a012

37. Craft NE, Soares JH. Relative solubility, stability, and absorptivity of lutein and beta-carotene in organic-solvents. J Agric Food Chem (1992) 40:431-4. doi:10.1021/jf00015a013

38. Lopez N, Puertolas E, Hernandez-Orte P, Alvarez I, Raso J. Effect of a pulsed electric field treatment on the anthocyanins composition and other quality parameters of Cabernet Sauvignon freshly fermented model wines obtained after different maceration times. LWT-Food Sci Technol (2009) 42:1225-31. doi:10.1016/j.lwt.2009.03.009

39. Luengo E, Alvarez I, Raso J. Improving the pressing extraction of polyphenols of orange peel by pulsed electric fields. Innov Food Sci Emerg Technol (2013) 17:79-84. doi:10.1016/j.ifset.2012.10.005
40. Grimi N, Mamouni F, Lebovka N, Vorobiev E, Vaxelaire J. Impact of apple processing modes on extracted juice quality: pressing assisted by pulsed electric fields. J Food Eng (2011) 103:52-61. doi:10.1016/j.jfoodeng.2010.09.019

Conflict of Interest Statement: The authors declare that the research was conducted in the absence of any commercial or financial relationships that could be construed as a potential conflict of interest.

Received: 27 May 2014; accepted: 23 July 2014; published online: 12 August 2014. Citation: Luengo E, Álvarez I and Raso J (2014) Improving carotenoid extraction from tomato waste by pulsed electric fields. Front. Nutr. 1:12. doi: 10.3389/fnut.2014.00012 This article was submitted to Nutrition and Food Science Technology, a section of the journal Frontiers in Nutrition.

Copyright (C) 2014 Luengo, Álvarez and Raso. This is an open-access article distributed under the terms of the Creative Commons Attribution License (CC BY). The use, distribution or reproduction in other forums is permitted, provided the original author(s) or licensor are credited and that the original publication in this journal is cited, in accordance with accepted academic practice. No use, distribution or reproduction is permitted which does not comply with these terms. 